\title{
Facies control on geochemistry of the Mesoarchean carbonate platform at Woman Lake (Canada)
}

\author{
B. RAMSAY ${ }^{1 *}$, P. FRALICK ${ }^{1}$, P. BIELSKI ${ }^{1}$, L. PATRY ${ }^{2}$, \\ P. SANSJOFRE ${ }^{3}$, AND S.V. LALONDE ${ }^{3}$ \\ ${ }^{1}$ Lakehead University, Thunder Bay, ON, Canada, \\ (*Correspondence: bjramsay@lakeheadu.ca) \\ ${ }^{2}$ CNRS-UMR6538 Géosciences Océan, IUEM, 29280, \\ Plouzané, France \\ ${ }^{3}$ Muséum National d'Histoire Naturelle, 75005, Paris, \\ France
}

The Mesoarchean carbonate platform at Woman Lake, Ontario, Canada, presents a unique opportunity to fill a 130 million year knowledge gap on early carbonate sedimentology and ocean chemistry evolution between similar occurrences at Steep Rock Lake (2.80Ga) [1] and Red Lake (2.93Ga)[2]. Stromatolitic carbonates have previously been recognized at Woman Lake [3] and is among one of the first thick carbonate platforms to develop in the Precambrian at $2857 \pm 5 \mathrm{Ma}$ (this study). We performed new field, petrographic, and geochemical investigations to better understand the paleoenvironmental context of this understudied locality.

At the base of the carbonate platform, lying atop rhyolitic Archean basement, are stratifera mats interbedded with thin beds of massive carbonate grainstone (CG), followed by pustular stromatolites (PS), which gradually become larger domes, then smaller bioherms with digitate and pseudocolumnar stromatolites and cross stratified CG. A variety of fenestral microbialites overly this unit, including thrombolites, stromatactis-bearing colloforms, and digitate stromatolites. This is followed by an alternating succession of PS and CG. Evidence here supports a tidally influenced coast with fluctuating sea-level and water energy.

The diverse carbonate facies demonstrate geochemical features reminiscent of both Archean and modern signatures in shale normalized REE spectra. Trace element and isotopic data indicate that the carbonates precipitated from a mixture of two different fluids: anoxic seawater that carried a positive Eu anomaly, and oxygenated waters that imparted significant negative $\mathrm{Ce}$ anomalies, plus a mixture of the two. At fine spatial scales, data from LA-ICP-MS and micro-sampling indicate important compositional differences between organic-rich microbial carbonates, their organic-poor equivalents, and the stromatactis.

Importantly, the Woman Lake carbonate platform provides context for and evidence of free oxygen present approximately 500 million years before the Great Oxidation Event.

[1] Fralick \& Riding (2015) Earth Sci. Rev. 151, 132-175. [2] Mcintyre \& Fralick (2017) The Depositional Record 3(2), 258-287 [3] Hofmann, Thurston, \& Wallace (1985) GSA Spec. Pub. 28, 125-132. 